\title{
Genetic Mapping of the pvr1 Locus in Capsicum spp. and Evidence That Distinct Potyvirus Resistance Loci Control Responses That Differ at the Whole Plant and Cellular Levels
}

\author{
John F. Murphy, James R. Blauth, Kevin D. Livingstone, Vincent K. Lackney, and Molly Kyle Jahn \\ Department of Plant Breeding and Biometry, Cornell University, Ithaca, NY 14853, U.S.A. \\ Accepted 8 July 1998.
}

\begin{abstract}
Two unlinked, recessive loci have been characterized in Capsicum spp. that independently confer distinct types of resistance to pepper mottle potyvirus (PepMoV). The first locus, from $C$. annuum cv. Avelar, affected the spread of PepMoV through the plant and had no discernible effect on tobacco etch potyvirus (HAT isolate; TEV-HAT) infection (J. F. Murphy and M. K. Kyle, Phytopathology 85:561-566, 1995). The second locus, found in $C$. chinense PI 159236 and PI 152225, interfered with PepMoV and TEV-HAT infection in plants and in isolated protoplasts. The resistant responses displayed by the $C$. chinense accessions to PepMoV and TEV-HAT appeared indistinguishable; however, these accessions were both susceptible to a second isolate of TEV, TEV-Mex21. We propose the symbols pvr1 for recessive PepMoV and TEV resistance from the $C$. chinense accessions and pvr3 for recessive PepMoV resistance from Avelar. pvr1 has been genetically mapped to a small linkage group with synteny to the short arm of tomato chromosome 3 .
\end{abstract}

Cosegregation of genes for resistance to several distinct plant viruses has been observed in a number of crop plants, but the genetic basis for this observation is not well established (Caranta and Palloix 1996; Cockerham 1970; Cook 1960; Fisher and Kyle 1994, 1996; Holmes 1961; Kyle and Provvidenti 1993; Provvidenti et al. 1983). We have investigated a number of examples of genetic resistance to more than one virus conditioned by a simply inherited factor, i.e., a single or complex locus. To date, the clearest examples involve members of the Potyviridae, single-stranded, plus-sense RNA viruses that constitute the largest and perhaps most economically destructive family of plant viruses. The large number of family members suggests that the family may have undergone extensive adaptive radiation, which could account for the

Corresponding author: Molly Kyle Jahn

E-mail address: mmk9@cornell.edu

Present address of J. F. Murphy: Department of Plant Pathology, Auburn University, AL 36849, U.S.A.

Present address of J. R. Blauth: Division of Biological Sciences, Alfred University, Alfred, NY 14802, U.S.A. relatively common observation of simply inherited, multivirus resistance (M. Marston and M. Jahn, unpublished data).

Information available thus far suggests that the genetic basis of cosegregation of resistance to related potyviruses is diverse. In pea (Pisum sativum) two clusters of distinct, tightly linked recessive genes confer resistance to overlapping sets of potyviruses (Kyle and Provvidenti 1993). Each gene in a cluster apparently confers resistance to one virus, although resistance to bean yellow mosaic virus and resistance to watermelon mosaic virus 2 attributed to the mo allele have not been separated to date. In contrast, extensive efforts in bean (Phaseolus vulgaris) to demonstrate that distinct factors account for cosegregation of dominant conditional resistance to nine potyviruses have not been successful (Fisher and Kyle 1994). These results are consistent with the hypothesis that, in this case, a single simple or complex locus may account for resistance.

Cosegregation of resistance to three potyviruses, including pepper mottle virus (PepMoV), tobacco etch virus (TEV), and potato virus Y (PVY), has been observed in pepper (Capsicum spp.) for many years (e.g., Cook 1960). These three pandemic viruses regularly cause significant crop losses, while at least two other potyviruses, chili veinal mottle virus and pepper veinal mottle virus, are of regional importance (Abdalla et al. 1991; Nagai and Smith 1968; Palloix 1992; Watterson 1993; Yoon et al. 1989; Zitter 1972, 1973). Because losses to viral diseases define the primary limitation to production of this crop, much effort has been directed toward the identification of sources of resistance to these potyviruses for the development of resistant pepper cultivars (Watterson 1993). A number of Capsicum genotypes are resistant to various ranges of potyviral isolates currently considered to be strains of PepMoV, TEV, and PVY, and a number of resistance genes have been identified to which resistance to more than one virus is attributed (Cook and Anderson 1959; Cook 1961; Dogimont et al. 1996; Kuhn et al. 1989; Kyle and Palloix 1997; Nagai and Smith 1968; Sowell and Demski 1977; Zitter 1972). The relationships among these genes have been confused, however, by the involvement of several viruses, each with several strains that can be difficult to distinguish. Further, terms used to describe specific resistance phenotypes have been too vague to allow definitive comparisons.

This report focuses on resistance, defined inclusively, that historically has been attributed to a set of alleles at the locus 
designated et (Greenleaf 1956). Greenleaf described a recessive factor in $C$. annuum SC 46252 and named the allele $e t^{a}$ for resistance to tobacco etch virus, with the superscript denoting the species in which the gene was identified. In the same paper, he described monogenic recessive resistance to TEV found in $C$. chinense PI 152225 (classified as $C$. frutescens at the time) and named that allele $e t^{f}$. Later, this was renamed $e t^{c}$ to reflect the change in host taxonomic classification, and subsequently renamed $e t^{c 2}$ to distinguish it from resistance found in $C$. chinense PI 159236, attributed to an allele called $e t^{c l}$ (Greenleaf 1986). No evidence of allelism was presented to justify the designation of all of these factors as alleles at the et locus, and no evidence of distinction between $e t^{c l}$ and $e t^{c 2}$ was provided.

Additional alleles have been assigned to this locus, despite obvious phenotypic differences in resistance response and no evidence of allelism (Greenleaf 1986). Zitter and Cook (1973) reported that in addition to extreme resistance to PVY and TEV (Nagai and Smith 1968; Zitter 1972), C. annuum cv. Avelar showed monogenic recessive "tolerance" to PepMoV. Subramanya (1982) evaluated allelism between monogenic recessive resistance to PepMoV from C. chinense PI 159236, named $e t^{c l}$ by Greenleaf (1986) and $C$. annuum cv. Delray Bell, whose PepMoV resistance was derived from Avelar (Cook et al. 1977). Subramanya obtained susceptible $F_{1}$ hybrids, indicating independent sources of resistance. $F_{2}$ segregation, however, could not distinguish between two competing hypotheses of the genetics of the resistance. The first hypothesis was that the resistances from Avelar and PI 159236 were allelic, but that a negative intralocus interaction resulted in susceptibility in the $\mathrm{F}_{1}$. The alternative hypothesis was that the wild-type products of both loci were needed for successful infection of the host, hence homozygosity at either locus would be sufficient to block infection. In the former case, a $1 \mathrm{~S}: 1 \mathrm{R}$ segregation would be expected in an $\mathrm{F}_{2}$ population, while in the latter 9S:7R would be expected. These hypotheses could have been distinguished by crossing segregating individuals with a susceptible genotype and assessing segregation in the resulting progenies, but this was not done.

In a later review, Greenleaf (1986) assigned the symbol $e t^{a v}$ to the allele from Avelar conditioning resistance to PVY, PepMoV, and some isolates of TEV, and assumed that $e t^{a v}$ was allelic with $e t^{a}$. However, Zitter and Cook (1973) had shown that resistance to PVY and TEV in Avelar segregated independently from resistance to PepMoV. Consequently, in a recent review, Watterson (1993) assigned the symbol $p m v$ to the PepMoV resistance from Avelar.

The objectives of this study were to clarify the genetic relationships among potyvirus resistance genes currently designated $e t^{a v}, p m v, e t^{c l}$, and $e t^{c 2}$, and to examine the characteristics of the more extreme resistance response to PepMoV and TEV conditioned by $e t^{c l}$ and $e t^{c 2}$ at both the whole plant and cellular levels. We were also interested in determining whether the recessive PepMoV and TEV resistance in $C$. chinense PI 159236 and PI 152225 was related evolutionarily to multi-virus or other pathogen resistance genes ( $\mathrm{R}$ genes) occurring in other solanaceous species. Finally, the study of these single genes or clusters of functionally related, tightly linked genes that confer resistance to several pathogens may provide the genetic basis to address fundamental inquiries into the nature of both plant and viral mutations that inter- fere with pathogenic processes and/or define the specificity of these interactions.

\section{RESULTS}

Recessive resistance to PepMoV in $C$. annuum cv. Avelar and $C$. chinense is conferred by distinct unlinked loci.

After confirming that resistance to PepMoV in Avelar (Zitter and Cook 1973) and the C. chinense accessions PI 152225 and PI 159236 (Subramanya 1982) was monogenic recessive (Blauth 1994), we examined the allelic relationships among these resistance factors (Table 1). To evaluate allelism of PepMoV resistance in the two $C$. chinense accessions, (PI $152225 \times$ PI 159236) $F_{1}, F_{2}$, and $B C$ populations were screened with the virus (Table 1). All plants were uniformly resistant to PepMoV; no symptoms of any type developed nor did plants have detectable amounts of PepMoV coat protein (CP) antigen in noninoculated leaves when tested by enzymelinked immunosorbent assay (ELISA). Negative ELISA results were confirmed by immunoblot analysis of the same samples and by inoculation onto the susceptible genotype $C$. annuum cv. NuMex RNaky (RNaky), which was used as the susceptible parent throughout these studies (data not shown). These experiments demonstrated that the two $C$. chinense accessions were allelic for recessive PepMoV resistance (Table 1). In the course of characterizing pepper accessions used for linkage mapping, we also found that recessive PepMoV resistance from C. chinense PI 159234 was allelic to PI 159236 and PI 152225 (Blauth 1994).

$\mathrm{F}_{1}$ populations derived from crosses between Avelar and the two $C$. chinense accessions were all susceptible to PepMoV, developing systemic mottle similar to that on (RNaky $\times$ Ave-

Table 1. Responses of parental Capsicum lines and $\mathrm{F}_{1}, \mathrm{~F}_{2}$, and $\mathrm{BC}$ populations to inoculation with pepper mottle potyvirus

\begin{tabular}{lrrrr}
\hline & \multicolumn{2}{c}{ Phenotype $^{\mathrm{a}}$} & & \\
\cline { 2 - 3 } Genotype/population & S & R & Expected ratio & $P$ \\
\hline Avelar (Avlr) & 0 & 10 & $0: 1$ & \\
PI 159236 (236) & 0 & 10 & $0: 1$ & \\
PI 152225 (225) & 0 & 8 & $0: 1$ & \\
$($ Avlr $\times 236) \mathrm{F}_{1}$ & 12 & 0 & $1: 0$ & \\
$($ Avlr $\times 225) \mathrm{F}_{1}$ & 9 & 0 & $1: 0$ & \\
$($ Avlr $\times 236) \mathrm{F}_{2}$ & 30 & 72 & $9: 7$ & $<0.005$ \\
$($ Avlr $\times 225) \mathrm{F}_{2}$ & 53 & 49 & $9: 7$ & 0.41 \\
$($ Avlr $\times 236) \times$ Avlr & 26 & 32 & $1: 1$ & 0.45 \\
$($ Avlr $\times 225) \times$ Avlr & 32 & 28 & $1: 1$ & 0.63 \\
$($ Avlr $\times 236) \times 236$ & 12 & 14 & $1: 1$ & 0.71 \\
$($ Avlr $\times 225) \times 225$ & 15 & 37 & $1: 1$ & $<0.005$ \\
$(225 \times 236) \mathrm{F}_{1}$ & 0 & 12 & $0: 1$ & \\
$(225 \times 236) \mathrm{F}_{2}$ & 0 & $108^{\mathrm{b}}$ & $0: 1$ & \\
$(225 \times 236) \times 225$ & 0 & $60^{\mathrm{b}}$ & $0: 1$ & \\
$(225 \times 236) \times 236$ & 0 & $60^{\mathrm{b}}$ & $0: 1$ & \\
\hline
\end{tabular}

${ }^{a} \mathrm{~S}=$ susceptible, $\mathrm{R}=$ resistant, based on presence or absence of viral symptoms on young, noninoculated leaves by 35 days postinoculation. All parent and $F_{1}$ results were confirmed by enzymelinked immunosorbent assay (ELISA) analysis of noninoculated leaves.

${ }^{b}$ Determination of virus infection, in addition to phenotypic response and ELISA analysis, was confirmed by immunoblot analysis of noninoculated leaves and use of noninoculated leaves as inoculum applied to a susceptible genotype. 
lar) $\mathrm{F}_{1}$ plants. PepMoV $\mathrm{CP}$ accumulation in noninoculated leaves was similar to that in the susceptible control (data not shown), demonstrating that PepMoV resistance in Avelar and the $C$. chinense accessions was conferred by distinct factors. The $F_{2}$ population derived from the (Avelar $\times$ PI 152225) interspecific cross showed segregation consistent with a 9S:7R ratio, which was expected based on our hypothesis of two distinct unlinked recessive genes, while the (Avelar $\times$ PI 159236) $\mathrm{F}_{2}$ showed extreme skewing toward the resistant parent. Three of the four backcross populations showed segregation consistent with a $1 \mathrm{~S}: 1 \mathrm{R}$ ratio, the exception being (Avelar $\times$ PI $152225) \times$ PI 152225 , where skewing toward the $C$. chinense allele also occurred. In the two cases in which the segregation ratios were skewed, there was still unambiguous segregation (Table 1). If the resistances were allelic, the $\mathrm{F}_{1}$ should be uniformly resistant and no segregation should be observed in either an $\mathrm{F}_{2}$ population or populations derived from the backcross to the resistant parent. Therefore, we can conclude that the deviations from expected Mendelian ratios are probably population-specific effects due to the interspecific nature of the cross, and not cause for rejection of the specific hypothesis in question. These results are in agreement with those of a previous report for $\mathrm{F}_{2}$ and backcross populations derived from C. annuum cv. Delray Bell $\times$ PI 159236 (Subramanya 1982).

To further verify our hypothesis of two distinct and unlinked genes, $25 \mathrm{~F}_{2}$ families were generated from the cross $($ Avelar $\times$ PI 152225) $\times$ RNaky, inoculated with PepMoV, and scored for symptoms. If the resistance loci were unlinked, we would observe a ratio of 1 family segregating according to the ratio (9S:7R) : 2 families segregating (3S:1R) : 1 family uniformly susceptible (1S:0R). If the loci were linked, or there were a complex interaction as suggested by Subramanya (1982), most or all families would be segregating 3S:1R, or the population would otherwise deviate from the 1:2:1 ratio described above. In this case, eight families segregated consistent with a 9S:7R ratio, 12 families segregated consistent with a 3S:1R ratio, and five families were fully susceptible. This 8:12:5 segregation was consistent with a $1: 2: 1$ ratio at $P$ $=0.69$, confirming the hypothesis that the PepMoV resistance loci from Avelar and the $C$. chinense accessions are distinct and inherited independently. Based on these results, we declared two loci and re-designated the $C$. chinense allele $p v r l$ and the Avelar allele $p v r 3$, consistent with a recently accepted proposal for nomenclature of potyvirus resistance genes in Capsicum (Kyle and Palloix 1997).

\section{Resistant responses of the $C$. chinense accessions to PepMoV and TEV at the whole plant and cellular levels.}

The $C$. chinense parents, PI 152225 and PI 159236, and the susceptible control, RNaky, were inoculated with PepMoV, TEV-HAT, and TEV-Mex21 (Table 2). Neither PepMoV CP nor TEV-HAT CP were detected by ELISA in inoculated or noninoculated leaves of PI 152225 or PI 159236 plants, and no disease symptoms were observed up to 28 days postinoculation (dpi). Plants of the susceptible parent, RNaky, accumulated PepMoV CP and TEV-HAT CP to high levels in both inoculated and noninoculated leaves. In PepMoVinoculated RNaky plants, systemic vein clearing and mottle developed between 7 and $10 \mathrm{dpi}$, while those inoculated with TEV-HAT developed systemic veinclearing between 5 and 7 dpi, followed in younger leaves by systemic mosaic (Table 2).

In contrast to the resistance observed to PepMoV and TEVHAT, both $C$. chinense accessions and RNaky accumulated TEV-Mex21 CP to similar levels in noninoculated leaves, indicating that pvrl does not confer resistance to this isolate of TEV (Table 2). Inoculated leaves were not tested for the presence of CP because systemic symptoms developed. The young leaves of PI 152225 plants inoculated with TEV-Mex21 developed small chlorotic areas that occasionally persisted throughout the course of the experiment, while in other experiments PI 152225 plants appeared to recover from the disease. Nevertheless, TEV-Mex21 CP remained at high levels in all symptomless tissues tested. In PI 159236 plants inoculated with TEV-Mex21, a systemic mosaic developed in young leaves; decapitation of these plants resulted in extremely severe symptom expression in the regenerated tissues.

Since no PepMoV or TEV-HAT CP was detected in inoculated or noninoculated leaves of the $C$. chinense accessions, we evaluated whether the resistance could be observed at the cellular level. Protoplasts isolated from leaves of PI 159236 and PI 152225 plants were inoculated in vitro with PepMoV or TEV-HAT RNA. Each experiment included two controls: first, protoplasts isolated from the susceptible genotype, RNaky, were inoculated to show that the viral RNA used as inoculum was infectious; second, PI 152225 and PI 159236 protoplasts were inoculated with RNA from a virus to which

Table 2. Serological and symptomatic analysis of Capsicum genotypes inoculated with pepper mottle potyvirus (PepMoV) and two isolates of tobacco etch potyvirus (TEV), TEV-HAT and TEV-Mex21

\begin{tabular}{|c|c|c|c|c|c|}
\hline \multirow[b]{2}{*}{ Genotype } & \multirow[b]{2}{*}{ Virus } & \multirow[b]{2}{*}{ Symptoms $^{\mathbf{a}}$} & \multicolumn{2}{|c|}{ ELISA $^{b}$} & \multirow[b]{2}{*}{ No. infected/ No. inoculated } \\
\hline & & & Inoculated leaves & Noninoculated leaves & \\
\hline \multirow[t]{3}{*}{ RNaky } & PepMoV & $-1+$ & $1.475 \pm 0.136 d$ & $0.744 \pm 0.195^{\mathrm{d}}$ & $5 / 5$ \\
\hline & TEV-HAT & $-1+$ & $2.000 \pm 0.000 \mathrm{~d}$ & $1.622 \pm 0.339^{\mathrm{d}}$ & $5 / 5$ \\
\hline & TEV-Mex 21 & $-1+$ & Not tested & $2.000 \pm 0.000^{\mathrm{d}}$ & $5 / 5$ \\
\hline \multirow[t]{3}{*}{ PI 159236} & PepMoV & $-1-$ & $0.051 \pm 0.008$ & $0.094 \pm 0.045$ & $0 / 10$ \\
\hline & TEV-HAT & $-1-$ & $0.155 \pm 0.068$ & $0.039 \pm 0.028$ & $0 / 10$ \\
\hline & TEV-Mex 21 & $-/+$ & Not tested & $1.920 \pm 0.102^{\mathrm{d}}$ & $10 / 10$ \\
\hline \multirow[t]{3}{*}{ PI 152225} & PepMoV & $-1-$ & $0.076 \pm 0.055$ & $0.120 \pm 0.072$ & $0 / 11$ \\
\hline & TEV-HAT & $-1-$ & $0.180 \pm 0.101$ & $0.040 \pm 0.019$ & $0 / 12$ \\
\hline & TEV-Mex 21 & $-1+$ & Not tested & $1.963 \pm 0.095^{\mathrm{d}}$ & $10 / 10$ \\
\hline
\end{tabular}

\footnotetext{
a Appearance of symptoms on inoculated/noninoculated leaves.

${ }^{\mathrm{b}}$ Mean enzyme-linked immunosorbent assay (ELISA) absorbance value \pm standard deviation for inoculated leaves and noninoculated leaves sampled.

${ }^{\mathrm{c}}$ Numbers in parentheses indicate numbers of plants infected based on ELISA per numbers of plants inoculated.

${ }^{\mathrm{d}}$ Denotes the average absorbance reading is above the threshold value (the mean of mock-inoculated samples plus three standard deviations).
} 
the plants are susceptible, cucumber mosaic virus Fast New York isolate (CMV-Fny), to show that the isolated protoplasts could be infected and could accumulate viral CP. Protoplasts isolated from RNaky showed accumulation of PepMoV, TEV-

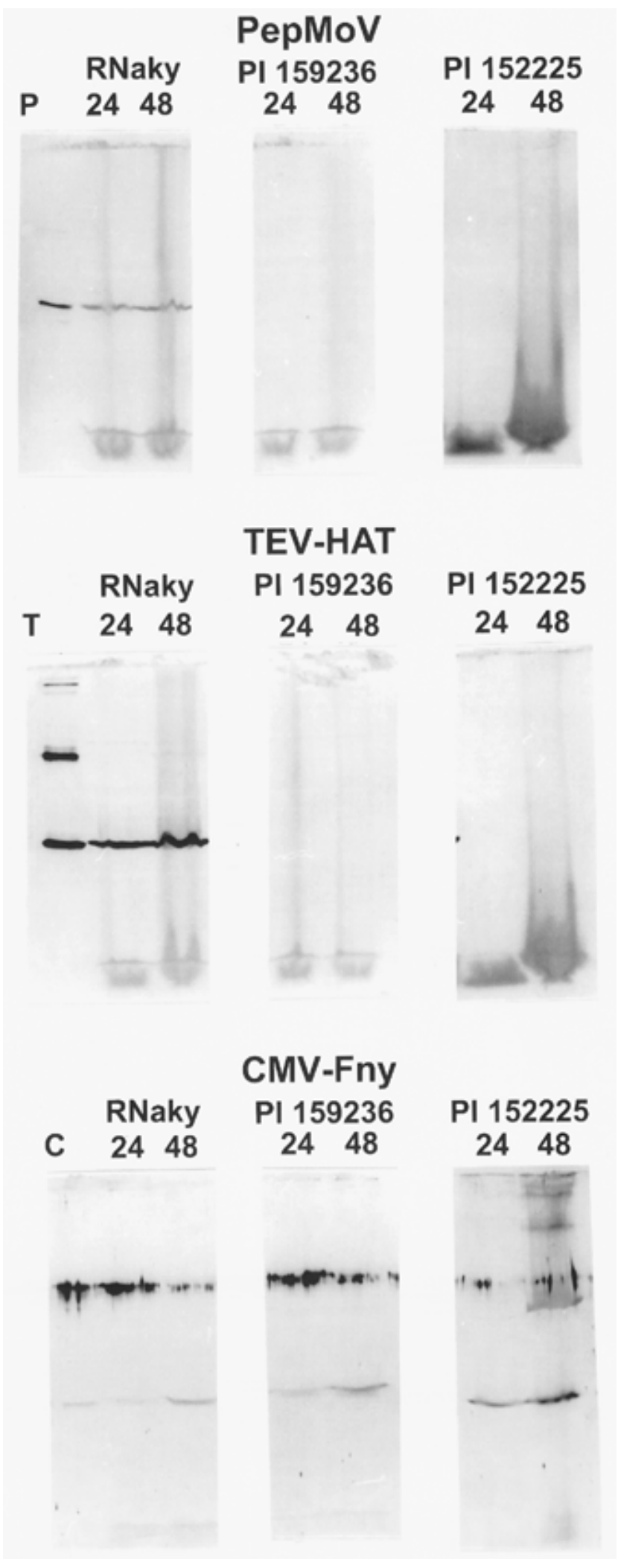

HAT, and CMV-Fny CP at 24 and 48 h post-inoculation (hpi), and CMV-Fny CP accumulation was observed in protoplasts from PI 152225 and PI 159236 at 24 and 48 hpi (Fig. 1). Neither PepMoV nor TEV-HAT CP accumulated to detectable levels in PI 152225 or PI 159236 protoplasts. This experiment was performed four times, and in each case, no PepMoV or TEV-HAT CP was detected in samples from the $C$. chinense protoplasts.

\section{Recessive TEV resistance in the $C$. chinense accessions is also allelic.}

After confirming that TEV resistance in the $C$. chinense accessions was recessive (Blauth 1994; Greenleaf 1956), we tested the allelic relationship between TEV resistance in these two sources. No symptoms were observed on (PI $152225 \times$ PI 159236) $F_{1}$ plants inoculated with TEV-HAT and no viral $C P$ was detected by ELISA, suggesting that recessive TEV-HAT resistance in these accessions was allelic.

\section{Molecular markers linked to recessive PepMoV resistance in $C$. chinense.}

An (RNaky $\times$ PI 159234) $F_{2}$ mapping population was screened with PepMoV to map pvrl. Fifty-eight of the 75 individuals were susceptible (either heterozygous or homozygous for the $C$. апnиum allele) and 17 were resistant (homozygous for the $C$. chinense allele). These data were not significantly different $(P=0.67)$ from the expected 3:1 ratio predicted by monogenic recessive resistance. This population was genotyped with 7 isozymes; 205 tomato genomic (TG), 76 tomato cDNA (CD/CT), 44 pepper genomic, and 2 pepper cDNA clones as probes in restriction fragment length polymorphism (RFLP); 66 random amplified polymorphic DNA (RAPD) primers; and 20 primer combinations in amplified fragment length polymorphism (AFLP) to generate 1,002 segregating markers as part of a larger comparative mapping effort in Capsicum spp. When these markers were split into linkage groups with criteria of a minimal LOD of 3 and maximum distance of $20 \mathrm{cM}$ to establish linkage, the linkage group with pvrl included only four other markers: TG56, TG135, CT128b, and A313, an AFLP marker (Table 3). Unfortunately, two of the markers in this linkage group were in the phase opposite pvrl (Table 3). No set of three markers from the five total could be ordered unambiguously $(\triangle \mathrm{LOD}<$ -3.0). A tentative assignment can be made, however, using TG56 and A313 as framework markers and accepting a small amount of variability in the position of pvrl (Fig. 2). This small linkage group remains unlinked in our mapping population despite efforts to use all polymorphic markers from the corresponding region in tomato (Fig. 2).

Fig. 1. Immunoblot analysis of protoplasts of Capsicum genotypes inoculated with pepper mottle potyvirus (PepMoV), tobacco etch potyvirus (TEV), or cucumber mosaic cucumovirus (CMV). Each lane represents a sample of 55,000 protoplasts collected from inoculated preparations of C. апnиum cv. RNaky or C. chinense PI 159236 or PI 152225 at 24 and $48 \mathrm{~h}$ post-inoculation. All samples were treated with lysis buffer (Laemmli 1970) and subjected to sodium dodecyl sulfatepolyacrylamide gel electrophoresis and electroblot transfer to nitrocellulose. Detection of viral coat protein antigen was according to Murphy and Kyle (1994). The first lane for each set of blots for each virus represents the respective purified virus standard $(50 \mathrm{ng} / \mathrm{ml})$. 


\section{DISCUSSION}

\section{Genetics of resistance to PepMoV and TEV \\ in Capsicum spp.}

We have shown via complementation and segregation analysis that alleles previously assigned to the et locus map to two distinct loci. In addition, the recessive allele from Avelar confers a response to PepMoV that is phenotypically distinct from the response conditioned by the allele found in C. chinense PI 152225 and PI 159236, as manifested by the differential response on leaves inoculated with PepMoV, protection afforded isolated protoplasts, and spectrum of resistance conferred. At the whole plant level, Murphy and Kyle (1995) have reported that Avelar plants inoculated with PepMoV developed diffuse chlorotic lesions on inoculated leaves, which progressively intensified, presumably a consequence of local infection. Further, PepMoV CP was detected in inoculated but not noninoculated leaves by ELISA. This is in contrast to the results observed with the $C$. chinense accessions, which showed no foliar symptoms and no detectable viral CP in inoculated or noninoculated leaves up to $28 \mathrm{dpi}$. Our results also show that protoplasts isolated from the $C$. chinense PIs do not support replication of PepMoV, even when inoculum consisted of viral RNA.

We also compared the TEV-HAT resistance phenotypes of Avelar and the $C$. chinense accessions at the whole plant levels. Avelar plants inoculated with TEV-HAT developed systemic vein clearing and mosaic, and TEV-HAT CP accumulated in noninoculated leaves to a level comparable to that seen in the susceptible genotype RNaky. Both $C$. chinense accessions were resistant to TEV-HAT. Hence, while these resistance loci are clearly distinct genetically, they overlap with respect to their resistance spectra, i.e., the range of potyviral isolates affected by the resistance allele. These results demonstrate that resistance factors that were previously thought to be allelic are instead independent loci conferring distinct types of resistance.

Further, we have shown that the alleles previously designated $e t^{c l}$ and $e t^{c 2}$ cannot be distinguished insofar as they were tested by either TEV strain-specificity or complementation analysis. In addition to the two isolates used in this study, we have tested two other TEV isolates reported to distinguish the two $C$. chinense accessions (TEV isolates $\mathrm{C} 1$ and Vil, obtained from L. Black, Louisiana State University, Baton Rouge) in an effort to examine the long-held assumption that there were two distinct alleles in PI 159236 and PI 152225. No differences between the two PIs with regard to virus isolate-specificity or phenotype in a resistant interaction were observed (J. Murphy and M. Jahn, unpublished data). In sus-

Table 3. Markers in the linkage group including $p v r 1$

\begin{tabular}{llcc}
\hline & & \multicolumn{2}{c}{ Pairwise linkage with pvr1 } \\
\cline { 3 - 4 } Marker & \multicolumn{1}{c}{ Phase $^{\mathbf{a}}$} & LOD & cM $^{\mathbf{b}}$ \\
\hline TG56 & Codominant & 9.42 & 5.4 \\
A313 & Codominant & 5.25 & 13.7 \\
TG135 & PI 159234 & 2.22 & 4.9 \\
CT128b & PI 159234 & 1.60 & 22.9 \\
pvr1 & RNaky & &
\end{tabular}

a Refers to whether genotype could be determined for both parents (codominant) or, if only one of the parents, which parent had the marker/phenotype.

${ }^{\mathrm{b}}$ Calculated with the Kosambi function. ceptible interactions in which both PIs became infected, however, there were consistent differences between the PIs in symptom intensity. PI 152225 was less symptomatic (sometimes symptomless), while PI 159236 generally developed more obvious symptoms. Our interpretation of these results is that the reduced symptom severity seen in PI 152225 is not due to allelic differences at the resistance locus, but rather due to effects of different genetic backgrounds. Although cosegregation of resistance to these two viruses has not been critically examined in large $F_{3}$ populations, a longstanding observation is that commercial pepper varieties bred for resistance to PepMoV with either of the $C$. chinense PIs appear to be uniformly resistant to a subset of TEV isolates (M. Jahn, data not presented).

In view of these data, we propose that a single symbol, $p v r 1$, be used for recessive resistance to both PepMoV and TEV-HAT from PI 159236 and PI 152225, until some distinguishing feature is identified. In addition, we have designated the independent source of resistance from Avelar, pvr3, according to the conventions proposed by the Committee for Capsicum Gene Nomenclature (Kyle and Palloix 1997).

\section{Cosegregation and redundancy of potyvirus resistance in Capsicum spp.}

Results from this study of PepMoV and TEV in Capsicum spp. are consistent with a pattern we have identified in another Potyviridae-plant system with better characterized genetics: members of the bean common mosaic virus subgroup and $P$. vulgaris. In $P$. vulgaris, as in Capsicum spp., monogenic inheritance of resistance to more than one potyvirus is observed (e.g., Fisher and Kyle 1994), together with a redundancy of resistance mechanisms to the same virus within a plant species or sexually compatible genus (Fisher and Kyle 1996).

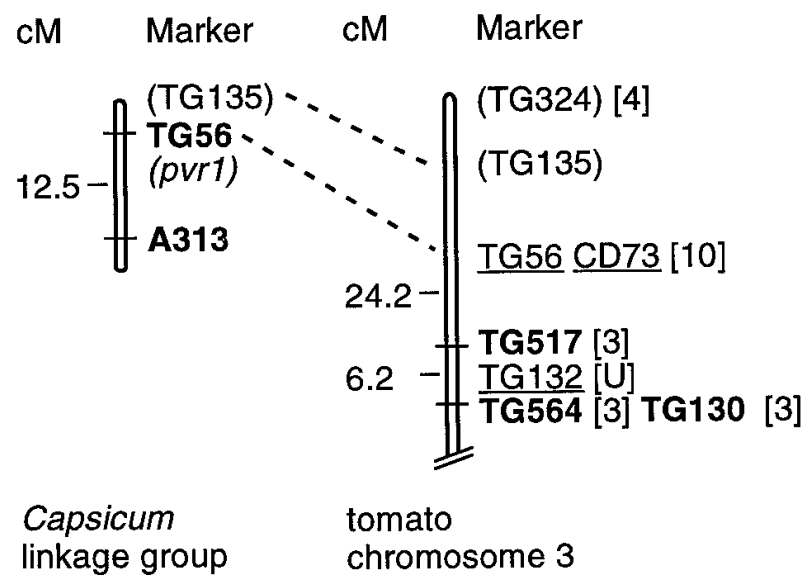

Fig. 2. Genetic mapping of the pvrl locus in Capsicum spp. and synteny with tomato. Map of tomato is modified from Pillen et al. (1996) to include only loci mapped in pepper. For both maps, loci in bold are framework markers whose positions have been established at $\Delta$ LOD <3.0, loci in parentheses are placed at lower LOD scores within the framework, and positions of underlined loci have been inferred from other maps. Numbers to the left are cM (Kosambi) between framework markers or to the end of the chromosome for the top of the tomato linkage group. The approximate position of pvrl $( \pm 5.4 \mathrm{cM}$ from TG56, $\pm 13.7 \mathrm{cM}$ from A313) is indicated. Number in brackets after tomato loci indicates the pepper linkage group where the restriction fragment length polymorphism detected by this probe maps and $U=$ unlinked. Dashed lines indicate positions of markers in common between the two groups. 
Other studies in Capsicum spp. have revealed additional cases of independent resistances to potyviruses. Dogimont et al. (1996) recently reported that $C$. annuum cv. CM 334 contains a recessive allele and a distinct, unlinked dominant allele that both confer resistance to a pathotype 0 isolate of PVY. They further reported that these two alleles are genetically distinct from the recessive PVY-0 resistance allele in $C$. annuum cv. Yolo Y, illustrating that redundancy of potyvirus resistance genes in Capsicum spp. is not uncommon. The observation of redundancy (i.e., more than one resistance gene or mechanism for a particular pathogen) derived from classical genetic analyses is consistent with emerging information from plant genome mapping and cloning efforts. While both genetic and molecular approaches make clear that there is considerable structural redundancy of resistance genes, the functional and evolutionary significance of this redundancy is still largely unresolved (e.g., Leister et al. 1998).

\section{Mechanisms of $p v r 1$ and $p v r 3$ resistance.}

Our results define a case in which there are at least two distinct mechanisms of resistance, yet these mechanisms affect a partially overlapping set of viral isolates. The assumption that distinct mechanisms are involved is based on clear phenotypic differences at the whole plant and cellular levels between the resistant responses conditioned by $p v r l$ and $p v r 3$. Resistance conditioned by pvrl appears to block the accumulation of virus at the cellular level, presumably at a relatively early process in the infection cycle. In contrast, results from a previous study (Murphy and Kyle 1995) indicated that Avelar can support accumulation of PepMoV in inoculated leaves and viral spread into the vascular system, but virus does not appear to spread into young noninoculated leaves. Despite these functional differences, both loci confer resistance to PepMoV.

While myriad resistance mechanisms against plant viruses are hypothesized, relatively few endogenous plant genes have been observed to condition a cellular resistance to infection when viral RNA was used as inoculum (Adams et al. 1986; Deom et al. 1997; Fraser 1990; Kiefer et al. 1984; Maule et al. 1980). PI 152225 and PI 159236 protoplasts resisted infection by PepMoV and TEV-HAT, even when inoculum consisted of as much as $25 \mu \mathrm{g}$ of viral RNA or when samples containing 700,000 protoplasts from each of the genotypes were examined (J. Murphy and M. Jahn, unpublished data). These results contrast with those of Arroyo et al. (1996) studying the mechanism of PVY pathotype 0 resistance conferred by the $y^{a}$ $\left(p v r 2^{l}\right)$ locus, where resistance is apparently due to impaired cell-to-cell movement of the virus. Cellular resistance certainly has the potential to more effectively reduce inoculum reservoirs than some movement-based forms of resistance, e.g., Avelar's resistance to PepMoV. This point is illustrated by results of coinoculation studies: when pvr3 / pvr3 PepMoV-resistant plants are co-infected with PepMoV and CMV, $\mathrm{PepMoV}$ is no longer restricted in its ability to systemically infect the plant (Murphy and Kyle 1995).

We have previously suggested that host genes or gene families that distinguish sets of pathogens may be used to identify conserved features of pathogenesis (Fisher and Kyle 1994, 1996). The increasing availability of reliable infectious transcripts and full-length clones of potyviruses, the ability to precisely manipulate these clones, and the availability of wellcharacterized host genes expressed at the whole plant and protoplast levels that specifically alter the plant-viral interaction should allow the identification of the viral determinants that are critical in the resistant response. Further characterization of these resistances will also identify the wild-type host components necessary for successful viral infection that are affected by mutations such as pvrl or pvr3. Knowledge of the conserved features of pathogenesis and/or the mechanisms whereby $p v r 1$ and $p v r 3$ restrict viral replication and movement, respectively, may define targets for engineered disease resistance strategies that could result in an even greater spectrum of resistance than offered by nature.

\section{Mapping of the pvr1 locus.}

The linkage group containing pvrl is one of two smaller linkage groups in an otherwise moderate to high density, 12 linkage group map of pepper (K. D. Livingstone and M. K. Jahn, unpublished). Two of the tomato clones linked to $p v r 1$ originate from the short arm of tomato chromosome 3 (Pillen et al. 1996), indicating possible synteny between the region of the Capsicum genome containing pvrl and this chromosome in tomato (Fig. 2). Examination of the location of RFLP detected by TG324, CD73, and TG132 in pepper shows that while all these clones produced segregating RFLP, their locations were spread among two other pepper linkage groups and one remains unlinked (Fig. 2). Hence, the region from TG517 to the telomere of chromosome 3 may be one of only two regions of the tomato genome that have not been preserved in content or order since the divergence of tomato and pepper (K. D. Livingstone and M. K. Jahn, unpublished). However, the TG135-TG56 linkage does suggest that this smaller portion of chromosome 3 has been preserved, and the linkage of these markers to $p v r l$ in pepper suggests that a homolog may be present in tomato on chromosome 3.

While no resistance genes currently map to the syntenic region in tomato, the genetic resources in Lycopersicon spp. for potyvirus resistance have not been systematically evaluated. Monogenic recessive resistance to TEV has recently been reported in a wild tomato accession, Lycopersicon hirsutum PI 247087 (Légnani et al. 1996), and introgression lines are available that will allow a direct comparison to be made between the location of $p v r l$ and the location of this factor for TEV resistance. More generally, we have begun systematic studies of potyvirus-Solanaceae interactions, e.g., SolanumCapsicum (Valkonen et al. 1996), to generate the comparative biology necessary to ascertain the extent to which genetic or genomic results from one solanaceous species are relevant to other species in the family.

In conclusion, while the elucidation of the genetic fine structure of the pvrl and pvr3 loci still awaits, this study sheds light on the genetic and mechanistic bases for resistance to two potyviruses in Capsicum.

\section{MATERIALS AND METHODS}

\section{Germplasm and genetic populations.}

Seeds of the susceptible parent, $C$. annuum cv. NuMex RNaky (Nakayama and Matta 1985), were provided by Fernando Loaiza-Figueroa, Asgrow Seed Co., San Juan Bautista, CA, and those of $C$. annuum cv. Avelar (C71 F243-3) and $C$. chinense PI 152225 (PC88 14279) were obtained from Robert Heisey, Asgrow Seed Co., San Juan Bautista, CA. Seeds of $C$. 
chinense PI 159236 (89GH282-9) were obtained from the USDA Southern Regional Plant Introduction Station, Experiment, GA. Seeds of C. chinense PI 159234 (CA4) were obtained from Steven Tanksley, Cornell University, Ithaca, NY. Plants from each accession were grown and checked for type, and a representative individual was self-pollinated once to establish parental lines before crosses were made.

For allele tests, the resistant parents were intercrossed and $\mathrm{F}_{2}$ and reciprocal backcross populations were generated from each cross. To test for independent segregation of PepMoV resistance from Avelar and the $C$. chinense accessions, (Avelar $\times$ PI 152225) $\times$ RNaky plants were self-pollinated to generate $\mathrm{F}_{2}$ families segregating for PepMoV resistance. Linkage mapping of PepMoV resistance in $C$. chinense was carried out with $\mathrm{F}_{2}$ plants derived from a cross between RNaky and $C$. chinense PI 159234 (utilized as a parent in linkage mapping studies; Tanksley et al. 1988; Prince et al. 1993; K. Livingstone and M. Jahn, unpublished data). $\mathrm{F}_{2}$ plants were screened with PepMoV and self-pollinated to generate $F_{3}$ families. All crosses were done by hand pollination in greenhouses with controlled temperature and supplemental lighting.

\section{Viral cultures and inoculation.}

PepMoV isolate V-1182 from Florida was provided by T. A. Zitter, Cornell University, Ithaca, NY. TEV-HAT was provided by T. P. Pirone, University of Kentucky, Lexington. TEV-Mex21 was provided by L. Black. PepMoV and TEVHAT were maintained in RNaky plants, and TEV-Mex21 was maintained in PI 159236 plants in the greenhouse. CMV-Fny was provided by R. Provvidenti, NYSAES, Cornell University, Geneva, NY, and maintained in squash. Prior to germination for virus screens, seeds were treated for 5 min with $10 \%$ Clorox bleach, rinsed in distilled water, and placed on moistened blotting paper in petri dishes. Seedlings were planted in Cornell mix in a growth chamber once the radicle emerged, and grown under $16 \mathrm{~h}$ light $/ 8 \mathrm{~h}$ dark at 27 and $22^{\circ} \mathrm{C}$, respectively, with mixed fluorescent and incandescent illumination. At the four- to eight-leaf stage, leaves 1 and 2 (the oldest pair of leaves) were dusted with Carborundum and inoculated with PepMoV- or TEV-infected RNaky leaf tissue ground in 0.05 M potassium phosphate buffer, $\mathrm{pH} 8.0$ (approximately 1:10 $\mathrm{wt} / \mathrm{vol}$ dilution). One week later, the second pair of leaves was inoculated to minimize any chance that plants escaped infection. Plants were scored for symptoms on inoculated and noninoculated leaves and evaluated by ELISA 2 to 4 weeks after the second inoculation.

\section{ELISA.}

PepMoV antiserum was provided by T. A. Zitter; TEV antiserum was obtained from the American Type Culture Collection, Rockville, MD. For studies of responses of parental lines to inoculation, analysis of leaf pairs included leaves 1 and 2 (the inoculated leaves) and leaves 7 and 8 (the third pair of noninoculated leaves above the inoculated leaves). Inoculated leaves were washed in a dilute solution of detergent and thoroughly rinsed in lukewarm tap water prior to processing to ensure the removal of residual viral CP. For inheritance and allelism studies, noninoculated leaves were tested for viral $\mathrm{CP}$ by ELISA. Samples consisted of one leaf from the first or second pair of noninoculated leaves above the inoculated leaves, and one from the third or fourth pair of noninoculated leaves above the inoculated leaves (depending on developmental state of the plants in each experiment). Leaf samples were processed according to Murphy and Kyle (1995) and viral CP was detected by direct double antibody sandwich ELISA (Clark and Adams 1977; Murphy and Kyle 1995). ELISA absorbance values were judged positive if they were greater than the mean absorbance value for corresponding leaves of mock-inoculated control plants plus three standard deviations.

\section{Protoplast isolation and inoculation.}

Isolation of protoplasts from RNaky, PI 152225, and PI 159236 plants and their subsequent inoculation with viral RNA were according to Murphy and Kyle (1994). Protoplast samples (approximately 55,000 protoplasts per sample) were collected at 24 and 48 hpi. Protoplasts were gently pelleted in a 1.5-ml Eppendorf tube with several pulses of centrifugation at 2,000 to 3,000 rpm (Sorvall MC 12V Microcentrifuge, Sorvall Centrifuges, Newtown, CT), the supernatant was removed, and the protoplasts were lysed by addition of $2 \times$ strength dissociation buffer (Laemmli 1970) and incubation in boiling water for $2 \mathrm{~min}$. Each sample was then stored at $-80^{\circ} \mathrm{C}$ until analyzed by sodium dodecyl sulfate-polyacrylamide gel electrophoresis and immunoblot analysis (Murphy and Kyle 1994).

\section{Mapping methods.}

DNA was extracted from leaves (Prince et al. 1997). All restriction digests were done with $10 \mu \mathrm{g}$ of pepper DNA and 2.0 $\mathrm{U}$ of restriction enzyme per $\mu \mathrm{g}$ of DNA. Digests were run in $1 \%$ agarose gels in $1 \times$ neutral electrophoresis buffer $(0.1 \mathrm{M}$ Tris, $1 \mathrm{mM}$ EDTA, and $12.5 \mathrm{mM}$ sodium acetate, $\mathrm{pH} 8.1$ ) overnight at $30 \mathrm{~V}$. Membranes were prepared according to the Hybond $\mathrm{N}^{+}$hybridization membrane protocol (Amersham, Buckinghamshire, UK).

Membranes containing DNA from parental pepper lines (survey filters) were prepared to check for polymorphism between parental DNAs digested with 12 restriction enzymes (DraI, EcoRI, EcoRV, HindIII, BstN1, TaqI, XbaI, BamHI, $B g l \mathrm{II}, B c l \mathrm{I}, S a c \mathrm{I}$, and $S t u \mathrm{I})$. To generate segregation data, membranes were prepared containing DNA from both parents and $75\left(\right.$ RNaky $\times$ PI 159234) $F_{2}$ progeny digested with the same restriction enzyme $\left(\mathrm{F}_{2}\right.$ filters). The filters were prehybridized for at least $4 \mathrm{~h}$ in $70 \mathrm{ml}$ of hybridization buffer. For RFLP mapping, a combination of pepper and tomato clones were used to probe the filters: pepper random genomic DNA (PG), tomato random genomic DNA (TG), tomato leaf epidermal cDNA (CD and CT), and pepper leaf epidermal cDNA (PC). Inserts in the clones were amplified by the polymerase chain reaction (Saiki et al. 1988), purified on Sephadex G50 spin columns equilibrated with Tris-EDTA buffer, and used as templates to generate probes by random hexamer labeling according to Feinberg and Vogelstein (1983) except that twice as much DNA (200 ng), labeling solution $(22 \mu \mathrm{l})$, Klenow enzyme $(4 \mu \mathrm{l})$, and ${ }^{32} \mathrm{P}-\mathrm{dCTP}(0.1 \mathrm{mCi})$ were used in each reaction. After a $90-\mathrm{min}$ incubation at $37^{\circ} \mathrm{C}$, probes were purified on Sephadex G50 spin columns in 1\% sodium dodecyl sulfate and $25 \mathrm{mM}$ EDTA at 2,500 rpm (Sorvall MC 12V Microcentrifuge) for $8 \mathrm{~min}$, denatured by heating at $100^{\circ} \mathrm{C}$ for $10 \mathrm{~min}$, and then added to the hybridization buffer. Hybridization was carried out overnight at $65^{\circ} \mathrm{C}$. Filters were washed with one 
low stringency $(2 \times \mathrm{SSC} ;[1 \times \mathrm{SSC}$ is $0.15 \mathrm{M} \mathrm{NaCl}$ plus 0.015 $\mathrm{M}$ sodium citrate]) and two moderate stringency ( $1 \times \mathrm{SSC})$ washes at $65^{\circ} \mathrm{C}$, and placed on Kodak XAR-5 film for 3 to 12 days, depending on the signal strength. Genotypes were scored for each segregating band; if there were more than two segregating bands for a particular probe, assignment of codominant pairs was not made until later in the mapping process when it was evident that the two alleles were mapping to the same approximate position.

AFLPs were generated by Keygene n.v. (Wageningen, The Netherlands) by the procedure of Vos et al. (1995).

Segregation analysis was performed with the MAPMAKER/EXP (version 3.0b) program (Lander et al. 1987). Loci were divided into linkage groups with the 'group' command at a minimum LOD score of 3.0 and a maximum recombination fraction of $20 \mathrm{cM}$ (Kosambi). All possible triplets from the group of five markers assigned to the pvrl linkage group were tested for a unique order with a criterion of $\Delta \mathrm{LOD}<-3.0$.

\section{ACKNOWLEDGMENTS}

We thank the following: George Moriarty and John Jantz for technical assistance; L. Black, R. Heisey, F. Loaiza-Figueroa, T. Pirone, R. Provvidenti, and T. A. Zitter for seed, viral isolates, and antisera; S. Tanksley for seed and tomato clones; and I. Paran, S. Czaplewski, R. Heisey, D. Kammerlohr, F. Loaiza-Figueroa, K. Owens, R. Provvidenti, R. Subramanya, and T. A. Zitter for critical reading of the manuscript. J. R. B. and K. D. L. were supported by a DOE/NSF/USDA grant to the Research Training Group in Molecular Mechanisms of Plant Processes and gifts from Marie Lavallard (J. R. B. and K. D. L.) and C. M. Werly (J. R. B.). J. F. M. was supported in part by a grant from the Cornell Center for Advanced Technology in Biotechnology, which is sponsored by the New York State Science and Technology Foundation, a consortium of industries, and the National Science Foundation. This research was supported in part by USDA NRI/CGP Award No. 94-37300-0333, BARD Award No. IS-2389-94, and the California Pepper Commission/California Pepper Improvement Foundation.

\section{LITERATURE CITED}

Abdalla, O. A., Desjardins, P. R., and Dodds, J. A. 1991. Identification, disease incidence, and distribution of viruses infecting peppers in California. Plant Dis. 75:1019-1023.

Adams, S. E., Jones, R. A. C., and Coutts, R. H. A. 1986. Expression of potato virus $\mathrm{X}$ resistant gene $R x$ in potato leaf protoplasts. J. Gen. Virol. 67:2341-2345.

Arroyo, R, Soto, M. J., Martínez-Zapatar, J. M., and Ponz, F. 1996. Impaired cell-to-cell movement of potato virus $\mathrm{Y}$ in pepper plants carrying the $y^{a}\left(p v r 2^{l}\right)$ resistance gene. Mol. Plant-Microbe Interact. 9:314-318

Blauth, J. R. 1994. Genetic analysis of resistance to pepper mottle potyvirus and tobacco etch potyvirus in pepper, genus Capsicum. Ph.D. thesis. Cornell University, Ithaca, NY.

Caranta, C., and Palloix, A. 1996. Both common and specific genetic factors are involved in polygenic resistance of pepper to several potyviruses. Theor. Appl. Genet. 92:15-20.

Clark, M. F., and Adams, A. N. 1977. Characteristics of the microplate method of enzyme-linked immunosorbent assay for the detection of plant viruses. J. Gen. Virol. 34:475-483.

Cockerham, G. 1970. Genetical studies on resistance to potato viruses X and Y. Heredity 25:309-348.

Cook, A. A. 1960. Genetics of resistance in Capsicum annuum to two virus diseases. Phytopathology 50:364-367.

Cook, A. A. 1961. A mutation for resistance to potato virus $\mathrm{Y}$ in pepper. Phytopathology 51:550-552.

Cook, A. A., and Anderson, C. W. 1959. Multiple virus disease resistance in a strain of Capsicum annuum. Phytopathology 49:198-201.
Cook, A. A., Zitter, T. A., and Ozaki, H. Y. 1977. Delray Bell, a virus resistant pepper for Florida. Fla. Agric. Exp. Stn. Circ. S-251.

Deom, C. M., Murphy, J. F., and Pagiuo, O. 1997. Resistance to tobacco etch virus in Capsicum annuum: Inhibition of virus RNA accumulation. Mol. Plant-Microbe Interact. 10:917-921.

Dogimont, C., Palloix, A., Daubèze, A. M., Marchoux, G., Gebre Selassie, K., and Pochard, E. 1996. Genetic analysis of broad-spectrum resistance to potyviruses using doubled haploid lines of pepper (Capsicum annuum L.). Euphytica 88:231-239.

Feinberg, A. P., and Vogelstein, B. 1983. A technique for radiolabelling DNA restriction fragments to a high specific activity. Anal. Biochem. 132:6-13.

Fisher, M. L., and Kyle, M. M. 1994. Inheritance of resistance to potyviruses in Phaseolus vulgaris L. III. Cosegregation of phenotypically similar dominant responses to nine potyviruses. Theor. Appl. Genet. 89:818-823.

Fisher, M. L., and Kyle, M. M. 1996. Inheritance of resistance to potyviruses in Phaseolus vulgaris L. IV. Inheritance, linkage relations, and environmental effects on systemic resistance to four potyviruses. Theor. Appl. Genet. 92:204-212.

Fraser, R. S. S. 1990. The genetics of resistance to plant viruses. Annu. Rev. Phytopathol. 28:179-200.

Greenleaf, W. H. 1956. Inheritance of resistance to tobacco-etch virus in Capsicum frutescens and in Capsicum annuum. Phytopathology 46:371-375.

Greenleaf, W. H. 1986. Pepper breeding. Page 67-134 in: Breeding Vegetable Crops. M. J. Bassett, ed. AVI Pub., Westport, CT.

Holmes, F. O. 1961. Concomitant inheritance of resistance to several viral diseases in tobacco. Virology 13:409-413.

Kiefer, M. C., Bruening, G. E., and Russell, M. L. 1984. RNA and capsid accumulation in cowpea protoplasts that are resistant to cowpea mosaic virus strain SB. Virology 137:371-381.

Kuhn, C. W., Nutter, F. W., Jr., and Padgett, G. B. 1989. Multiple levels of resistance to tobacco etch virus in pepper. Phytopathology 79:814818.

Kyle, M. M., and Palloix, A. 1997. Proposed revision of nomenclature for potyvirus resistance genes in Capsicum. Euphytica 97:183-188.

Kyle, M. M., and Provvidenti, R. 1993. Genetics of broad spectrum viral resistance in bean and pea. Pages 153-166 in: Resistance to Viral Disease of Vegetables: Genetics and Breeding. M. M. Kyle, ed. Timber Press, Portland, OR.

Laemmli, U. K. 1970. Cleavage of structural proteins during the assembly of the head of bacteriophage T4. Nature 227:680-685.

Lander, E. S., Green, P., Abrahamson, J., Barlow, A., Daly, M. J., Lincoln, S. E., and Newburg, L. 1987. MAPMAKER: An interactive computer package for constructing primary genetic linkage maps of experimental and natural populations. Genomics 1:174-181.

Légnani, R., Gognalons, P., Gébré Sélassié, K., Marchoux, G., Moretti, A., and Laterrot, H. 1996. Identification and characterization of resistance to tobacco etch virus in Lycopersicon species. Plant Dis. 80:306-309.

Leister, D., Kurth, J., Laurie, D. A., Yano, M., Sasaki, T., Devos, K., Graner, A., and Schulze-Lefert, P. 1998. Rapid reorganization of resistance gene homologues in cereal genomes. Proc. Natl. Acad. Sci. USA 95:370-375.

Maule, A. J., Boulton, M. I., and Wood, K. R. 1980. Resistance of cucumber protoplasts to cucumber mosaic virus: A comparative study. J. Gen. Virol. 51:271-279.

Murphy, J. F., and Kyle, M. M. 1994. Isolation and viral infection of Capsicum leaf protoplasts. Plant Cell Rep. 13:397-400.

Murphy, J. F., and Kyle, M. M. 1995. Alleviation of restricted systemic spread of pepper mottle potyvirus in Capsicum annuum cv. Avelar by coinfection with a cucumovirus. Phytopathology 85:561-566.

Nagai, H., and Smith, P. G. 1968. Reaction of pepper varieties to naturally occurring viruses in California. Plant Dis. Rep. 52:928-930.

Nakayama, R. M., and Matta, F. B. 1985. 'NuMex RNaky' chile pepper. HortScience 20:961-962.

Palloix, A. 1992. Diseases of pepper and perspectives for genetic control. Pages 120-126 in: VIII Eucarpia Meeting: Genetics and Breeding on Capsicum and Eggplant.

Pillen, K., Pineda, O., Lewis, C. B., and Tanksley, S. D. 1996. Status of genome mapping tools in the taxon Solanaceae. Pages 281-308 in: Genome Mapping in Plants. A. H. Paterson, ed. R. G. Landes, Austin, TX. 
Prince, J. P., Pochard, E., and Tanksley, S. D. 1993. Construction of a molecular linkage map of pepper and a comparison of synteny with tomato. Genome 36:404-417.

Prince, J. P., Zhang, Y., Radwanski, E. R., and Kyle, M. M. 1997. A high-yielding and versatile DNA extraction protocol for Capsicum. HortScience 32:937-939.

Provvidenti, R., Gonsalves, D., and Taiwo, M. A. 1983. Inheritance of resistance to blackeye cowpea mosaic and cowpea aphid-borne mosaic viruses in Phaseolus vulgaris. J. Hered. 74:60-61.

Saiki, R. K., Gelfand, D. H., Stoffel, S., Scharf, S. J., Higuchi, R., Horn, G. T., Mullis, K. B., and Erlich, H. A. 1988. Primer-directed enzymatic amplification of DNA with a thermostable DNA polymerase. Science (Washington, DC) 239:487-491.

Sowell, G., and Demski, J. W. 1977. Resistance of plant introductions of pepper to tobacco etch virus. Plant Dis. Rep. 61:146-148.

Subramanya, R. 1982. Relationship between tolerance and resistance to pepper mottle virus in a cross between Capsicum annuum L. $\times$ Capsicum chinense Jacq. Euphytica 31:461-464.

Tanksley, S. D., Bernatsky, R., Lapitan, N. L., and Prince, J. P. 1988. Conservation of gene repertoire but not gene order in pepper and tomato. Proc. Natl. Acad. Sci. USA 85:6419-6423.

Valkonen, J. P. T., Kyle, M. M., and Slack, S. 1996. Comparison of re- sistance to potyviruses within Solanaceae: Infection of potatoes with tobacco etch potyvirus and peppers with potato $\mathrm{A}$ and $\mathrm{Y}$ potyviruses. Ann. Appl. Biol. 129:25-38.

Vos, P., Hogers, R., Bleeker, M., Reijans, M., Van De Lee, T., Hornes, M., Frijters, A., Pot, J., Peleman, J., Kuiper, M., and Zabeau, M. 1995. AFLP: A new technique for DNA fingerprinting. Nucleic Acids Res. 23:4407-4414.

Watterson, J. C. 1993. Development and breeding of resistance to pepper and tomato viruses. Pages 80-101 in: Resistance to Viral Diseases of Vegetables: Genetics and Breeding. M. M. Kyle, ed. Timber Press, Portland, OR

Yoon, J. Y., Green, S. K., Tschanz, A. T., Tsou, S. C. S., and Chang, L. C. 1989. Pepper improvement for the tropics: Problems and the AVRDC approach. Pages 86-98 in: Tomato and pepper production in the tropics: International symposium on integrated management practices. T. D. Griggs and B. T. McLean, eds. AVRDC, Taipei, Taiwan.

Zitter, T. A. 1972. Naturally occurring pepper virus strains in south Florida. Plant Dis. Rep. 56:586-590.

Zitter, T. A. 1973. Further pepper virus identification and distribution studies in Florida. Plant Dis. Rep. 57:991-994.

Zitter, T. A., and Cook, A. A. 1973. Inheritance of tolerance to a pepper virus in Florida. Phytopathology 63:1211-1212. 